Original Research Article

\title{
Predicting the effectiveness of Test of Infant Motor Performance as an early marker of motor development delay in preterm infants
}

\author{
Diwanmal SB. ${ }^{1}$, Dharmayat SR. ${ }^{2}$, Biradi MK. ${ }^{3}$, Vanaki RN. ${ }^{4}$, Pol RR. ${ }^{5}$, Yelamali BC. ${ }^{6}$ \\ ${ }^{1}$ Dr. Suchitra Diwanmal, Consultant Pediatric Physiotherapist, Department of Pediatrics, S.N. Medical College \\ \& HSK Hospital, Bagalkot, ${ }^{2}$ Dr. Snehal Dharmayat, Associate Professor, KLE's University Institute of \\ Physiotherapy, Belagavi, ${ }^{3}$ Dr. Mahantesh Biradi, Consultant Physiotherapist, ${ }^{4}$ Dr. Raghavendra Vanaki, \\ Associate Professor, ${ }^{5}$ Dr. Ramesh Pol, Professor, ${ }^{6}$ Dr. Bhuvaneshwari Yelamali, Professor \& Head of the \\ Department, ${ }^{3-6}$ above four authors are attached with Department of Pediatrics, S.N. Medical College \& HSK \\ Hospital, Bagalkot, Karnataka, India
}

Address for Correspondence: Dr Raghavendra Vanaki, Associate Professor, Department of Pediatrics, S.N. Medical College \& HSK Hospital, Bagalkot-587103. Karnataka, India. Email- raghuvanaki@yahoo.co.in

\begin{abstract}
Objectives: The purpose of this study was to determine the effectiveness of Test of Infant Motor Performance (TIMP) in detecting motor developmental delay in preterm infants.Material and methods: The present study was conducted on 30 infants born preterm with corrected age of 2 months and follow up of TIMP at 4 months corrected age and Alberta Infant Motor Scale (AIMS) at 2, 4 and 6 months corrected age. Study period was January 2012 to December 2015.Results: Pearson product moment correlation coefficient used to assess the relationship between the raw scores of TIMP and AIMS percentile rank at corrected age of 2 and 4 months, was $0.757(\mathrm{p}<0.0001)$ and $0.874(\mathrm{p}<0.0001)$ respectively. An analysis of the sensitivity, specificity, positive predictive value and negative predictive value of various TIMP cutoff scores for comparison with AIMS scores above and below the $10^{\text {th }}$ percentile revealed the best TIMP score with a cutoff of -1 standard deviation below the mean. The results for comparison of 2, 4, 6 months corrected age AIMS data using Pearson chi square test was highly significant with p 0.001 at 2 months CA AIMS data with 4 months CA AIMS data.Conclusion and Interpretation:TIMP and AIMS are equally useful in the assessment of infant motor performance at 4 months of corrected age. A cutoff score of -1 SD from the mean on TIMP was a better predictor of developmental outcome in this study.
\end{abstract}

Key words: AIMS, Corrected age, Preterm infants, Test of Infant Motor Performance (TIMP)

\section{Introduction}

The word "preterm" is used to refer to infants born before 37 completed weeks of gestation [1].Preterm is defined as less than 37 weeks, very preterm is less than 32 weeks, and extremely preterm is defined as less than 28 weeks gestation[2]. Survival remains directly proportional to gestational age and birth weight. Years ago, prematurity was frequently a death sentence. Today, advances in antenatal medicine and neonatal intensive care, including more aggressive delivery room resuscitation,

Manuscript received: $09^{\text {th }}$ September 2017

Reviewed: $16^{\text {th }}$ September 2017

Author Corrected: $23^{\text {rd }}$ September 2017

Accepted for Publication: 30 $0^{\text {th }}$ September 2017 surfactant use, antenatal corticosteroid utilization, improved ventilator techniques, and nutritional management have successfully resulted in improved survival rates of preterm infants. But improvements in survival have not been accompanied by proportional reductions in the incidence of disability in this population. Thus, survival is not an adequate measure of success in these infants who remain at high risk for neurodevelopmental and behavioral morbidities.

The earliest possible identification of infants and children who exhibit serious developmental 
disabilities such as Cerebral Palsy and Mental Retardation is an important goal of pediatric health care practitioners.

The Test of Infant Motor Performance (TIMP) is a test of posture and movement in infants. The creators of the test are Physical therapists Susann K. Campbell, Gay L.Girolami and Thubi H.A Kolobe and occupational therapists Elizabeth $\mathrm{T}$. Osten and Mauren C. Lenke[3].

The TIMP is a test of postural and selective motor control needed for functional performance in daily life during early infancy. Test items have been shown to reflect the movement demands experienced by infants in naturalistic interactions with caregivers such as bathing, dressing and play.

The 42 items on the current version 5 of the TIMP divided into Observed (13 items) and Elicited items (29 items) provide a comprehensive assessment of developing head and trunk control as well as selective control of arms and legs from 34 weeks post conceptual age (PCA) through 4 months post term age in premature infants or up through 17 weeks chronological age for term born infants. The TIMP can be used with both full term and prematurely born infants and requires an average of 33 minutes to administer and score[4].

The Observed Items assess a spontaneously emitted behavior that includes selective control of fingers and ankles, midline head orientation and development of ballistic, oscillating and fidgety movements. The Elicited Items of the TIMP present infants with a variety of tasks to which they are expected to respond with appropriate postural alignment or movement.

Raw scores on the test are obtained by adding scores for all items. Observed items are scored 0 (not observed) or 1 (observed), Elicited Items have rating scales from 4-7 levels. Total raw score on version 5 can range from $0-142[4]$.

Alberta Infant Motor Scale (AIMS) is used as criterion referenced, Observational assessment scale. An AIMS was constructed by Piper MC, Darrah J in 1994. It assesses the infant's sequential development of motor milestones from term to independent walking (0-18 months) in terms of the progressive development and integration of antigravity muscular control in four postural positions: prone, supine, sitting, and standing.

\section{Aims \& Objectives}

This study intends to detect atypical motor development and identify the infants who have abnormal development as measured by TIMP by comparing it with AIMS at 2, 4 and 6 months of corrected ages. By this comparative study we can determine a preferable early intervention services for the developmentally delayed children.

\section{Materials \& Methods}

Place of study:

Infants were recruited (less than 37 completed weeks of gestation) from the Department of Pediatrics and Child Development Clinic, K.L.E's Dr Prabhakar Kore Hospital, Belagavi and at Department of Paediatrics, S.N. Medical College \& Hanagal Shri Kumareshwar Hospital Bagalkot.

\section{Type of the study:}

Observational study- Longitudinal study

Sampling method: Purposive sampling

\section{Sample collection:}

Infants (less than 37 completed weeks of gestation from corrected age of 2 to 6 months) were recruited as part of longitudinal study of performance with various degrees of risk for developmental delay using TIMP (as shown in table 1). Study period was January 2012 to December 2015.

30 infants were included in the study based on the sample size calculation, done using medcalc software at $99 \%$ confidence level, $90 \%$ power of the study and taking correlation co-efficient of $66.6 \%$.

\section{Inclusion criteria:}

Preterm infants born less than 37 completed weeks of gestation with corrected age of 2 months.

\section{Exclusion criteria:}

Infants with Brachial plexus injury, genetic disorders, congenital anomalies, congenital 
neuropathies, congenital myopathies, prolonged sedation, physiologically unstable or unstable vital parameters.

Research method: After parental consent all the preterm infants (born less than 37 completed weeks of gestation) of corrected age 2 months at the time of commencement of the study were tested. The 42-item TIMP was administered on the infant and scores were noted. Follow up was done at 4 months corrected age. At the same time the 58-item AIMS was administered on infants at corrected age of 2 months and follow up was done at 4 and 6 months corrected age.

TIMP assessment was started with observation of spontaneous activity (observed items). After recording initial observation continuous observation was done to score presence of observed items throughout the remainder of the test. No more than three trials were allowed for each elicited test item. Based on the infant's response, the best response observed was scored. Observed items were scored 0 (not observed) or 1 (observed). Elicited items were scored on 4-7 levels of rating scale.

Raw scores on the test were obtained by adding scores for all items and were compared with the scores of 2004 age standards for performance on the TIMP to know the infant's position related to the age. Based on the total raw score and standard deviation from the mean at respective ages, they were classified as far below average, below average, low average and average range[4].

AIMS assessment was done for only those items in the range most appropriate for the infant's

\section{Results}

The results of this study were analyzed in terms of Sensitivity, Specificity, PPV, NPV and diagnostic accuracy which were measured using TIMP and AIMS. The results were calculated separately at 2, 4, 6 months of age.

Sex distribution and gestational age: Total of 30 infants participated in the study. Out of which 23 males and 7 females with average gestational age of 34.43 weeks $(\mathrm{SD} \pm 1.43)$. The corrected age $(\mathrm{CA})$ was measured in months and days. The average $\mathrm{CA}$ at 2 months follow-up was 2 months and 6 days $(\mathrm{SD} \pm 4.5)$. The average $\mathrm{CA}$ at 4 months follow-up was 4 months and 4 days $(\mathrm{SD} \pm 3)$. The average $\mathrm{CA}$ at 6 months follow-up was 6 months and 5 days $(\mathrm{SD} \pm 4)$.

Average TIMP score at 2 months CA was $64.36(\mathrm{SD} \pm 15.36)$ and 4 months was $107.93(\mathrm{SD} \pm 14.63)$. Average percentile rank on AIMS at 2 months $\mathrm{CA}$ was $47 \%$ ( $\mathrm{SD} \pm 28.18)$, at 4 months $\mathrm{CA}$ was $59 \%(\mathrm{SD} \pm 25.91)$ and at 6 months CA was $63.5 \%$ ( $\mathrm{SD} \pm 22.40)$. (Table 1 )

Pediatric Review: International Journal of Pediatric Research Aailable online at: www.pediatricreview.in $574 \mid \mathrm{P}$ a g e developmental level. For each test item, the examiner must identify and observe 3 key descriptors: weight bearing, posture, and antigravity movements.

The scoring system entails a dichotomous choice for each test item, scored as "observed" or "not observed". Sum of the points was obtained in each position and sum of four positional scores was

The derived scores were used to calculate the percentile ranking of an individual infant which are in terms of within age group norms of normative

Statistical Analysis-Various statistical measures such as Mean, Standard deviation, Sensitivity, Specificity, Positive Predictive Value (PPV), Negative Predictive Value (NPV) along with the $95 \%$ confidence interval were utilized for this purpose for all the available scores in all the participants.

Data from participants i.e. gestational age (GA), corrected age (CA) at 2, 4, and 6 months, neonatal problems, TIMP score at 2 and 4 months $\mathrm{CA}$ and AIMS percentile rank at 2, 4, and 6 months CA were analyzed using mean and standard deviation (SD). Later the sensitivity, specificity, PPV, NPV was calculated to know the effectiveness of TIMP preterm infants. The observed percentile rank at 2,4,6 months CA of AIMS was compared with each other by using Chi square test to find out the significance of outcome. 
Correlation Analysis: The Pearson product moment correlation between the TIMP raw score and AIMS percentile rank at 2 months CA was $0.757(\mathrm{p}<0.0001)$. The correlation between the TIMP raw score and AIMS percentile rank at 4 months CA was $0.874(\mathrm{p}<0.0001)$.

Table-1 : Demographic data

\begin{tabular}{|c|c|}
\hline Data & Number of infants (n) \\
\hline Gender & \\
\hline Male & 23 \\
\hline Female & 07 \\
\hline $\begin{array}{l}\text { Gestational Age } \\
\text { (in weeks) }\end{array}$ & $34.43 \pm 1.43$ weeks \\
\hline $\begin{array}{l}\text { Corrected age (in months and days) } \\
2 \text { months } \\
4 \text { months }\end{array}$ & $\begin{array}{l}2 \text { months } 6 \text { days } \pm 4.5 \\
4 \text { months } 4 \text { days } \pm 3\end{array}$ \\
\hline 6 months & 6 months 5 days \pm 4 \\
\hline $\begin{array}{l}\text { Neonatal Problems\$ } \\
\text { Birth Asphyxia } \\
\text { Sepsis } \\
\text { Meconium Aspiration Syndrome } \\
\text { Hyperbilirubinemia } \\
\text { Hypoglycemia } \\
\text { Cephalhematoma } \\
\text { Respiratory Distress syndrome } \\
\text { GI bleed } \\
\text { Throbocytopenia } \\
\text { Hypocalcemia } \\
\text { (\$ - more than } 1 \text { problems in infant) }\end{array}$ & $\begin{array}{l}\text { Number of infants } \\
4 \\
8 \\
6 \\
7 \\
3 \\
5 \\
6 \\
3 \\
7 \\
4\end{array}$ \\
\hline $\begin{array}{l}\text { TIMP scores } \\
\text { CA } 2 \text { months }\end{array}$ & $64.36 \pm 15.36$ \\
\hline CA 4 months & $107.93 \pm 14.69$ \\
\hline $\begin{array}{l}\text { AIMS percentile rank } \\
\text { CA } 2 \text { months } \\
\text { CA } 4 \text { months }\end{array}$ & $\begin{array}{l}47 \% \pm 28.18 \\
59 \% \pm 25.91\end{array}$ \\
\hline CA 6 months & $63.50 \% \pm 22.40$ \\
\hline
\end{tabular}

Sensitivity, Specificity, PPV, NPV: To compare the TIMP results to known data on the AIMS regarding high risk for poor developmental outcome of infants at 2 and 4 months CA below $10^{\text {th }}$ percentile, TIMP scores using different cut off values $(-0.25,-0.50,-0.75,-1$ and -2 SDs from the mean) vs. the AIMS cut off value of below $10^{\text {th }}$ percentile were taken. (Table $2 \& 3$ )

AIMS percentile rank at 2, 4, 6 months corrected age: The observed percentile rank at 2 months CA of AIMS was compared with observed percentile rank at 4 months CA of AIMS by using Chi square test and the P-value was .001 which was highly significant, the observed percentile rank at 2 months CA of AIMS was compared with observed percentile rank at 6 months CA of AIMS by using Chi square test and the P-value was .575 which was not significant, the observed percentile rank at 4 months CA of AIMS was compared with observed percentile rank at 6 months $\mathrm{CA}$ by using Chi square test and the p-value .735 which was not significant(Table 4). 
Table-2: Summary of diagnostic efficiency of TIMP and AIMS below10th percentile at 2 months corrected age

\begin{tabular}{|c|c|c|c|c|c|}
\hline $\begin{array}{l}\text { TIMP cut-off } \\
\text { score }\end{array}$ & $\begin{array}{l}\text { Sensitivity } \\
(95 \% \mathrm{CI})\end{array}$ & $\begin{array}{l}\text { Specificity } \\
(95 \% \text { CI) }\end{array}$ & $\begin{array}{l}\text { PPV } \\
(95 \% \mathrm{CI})\end{array}$ & $\begin{array}{l}\text { NPV } \\
(95 \% \mathrm{CI})\end{array}$ & $\begin{array}{l}\text { Diagnostic } \\
\text { accuracy } \\
(95 \% \mathrm{CI})\end{array}$ \\
\hline-0.25 SD & $\begin{array}{l}100 \% \\
(64.57-100)\end{array}$ & $\begin{array}{l}60.87 \% \\
(40.79-77.84)\end{array}$ & $\begin{array}{l}43.75 \% \\
(23.1-66.82)\end{array}$ & $\begin{array}{l}100 \% \\
(78.47-100)\end{array}$ & $\begin{array}{l}70 \% \\
(52.12-83.34)\end{array}$ \\
\hline$-0.50 \mathrm{SD}$ & $\begin{array}{l}85.71 \% \\
(48.69-97.43)\end{array}$ & $\begin{array}{l}65.22 \% \\
(44.89-81.19)\end{array}$ & $\begin{array}{l}42.86 \% \\
(21.38-67.41)\end{array}$ & $\begin{array}{l}93.75 \% \\
(71.67-98.89)\end{array}$ & $\begin{array}{l}70 \% \\
(52.12-83.34)\end{array}$ \\
\hline$-0.75 \mathrm{SD}$ & $\begin{array}{l}85.71 \% \\
(48.69-97.43)\end{array}$ & $\begin{array}{l}82.61 \% \\
(62.86-93.02)\end{array}$ & $\begin{array}{l}60 \% \\
(31.27-83.18)\end{array}$ & $\begin{array}{l}95 \% \\
(76.39-99.11)\end{array}$ & $\begin{array}{l}83.33 \% \\
(66.44-92.66)\end{array}$ \\
\hline -1 SD & $\begin{array}{l}71.43 \% \\
(35.89-91.78)\end{array}$ & $\begin{array}{l}91.30 \% \\
(73.2-97.58)\end{array}$ & $\begin{array}{l}71.43 \% \\
(35.89-91.78)\end{array}$ & $\begin{array}{l}91.30 \% \\
(73.2-97.58)\end{array}$ & $\begin{array}{l}86.67 \% \\
(70.32-94.69)\end{array}$ \\
\hline-2 SD & inconclusive & inconclusive & inconclusive & inconclusive & Inconclusive \\
\hline
\end{tabular}

PPV- Positive Predictive Value, NPV- Negative Predicitve Value, CI-Confidence interval

Table-3: Summary of diagnostic efficiency of TIMP and AIMS below 10th percentile at 4 months corrected age

\begin{tabular}{|c|c|c|c|c|c|}
\hline $\begin{array}{l}\text { TIMP cut-off } \\
\text { score }\end{array}$ & $\begin{array}{l}\text { Sensitivity } \\
(95 \% C I)\end{array}$ & $\begin{array}{l}\text { Specificity } \\
(95 \% \text { CI) }\end{array}$ & $\begin{array}{l}\text { PPV } \\
(95 \% \mathrm{CI})\end{array}$ & $\begin{array}{l}\text { NPV } \\
(95 \% C I)\end{array}$ & $\begin{array}{l}\text { Diagnostic } \\
\text { accuracy } \\
(95 \% \mathrm{CI})\end{array}$ \\
\hline$-0.25 \mathrm{SD}$ & $\begin{array}{l}100 \% \\
(43.85-100)\end{array}$ & $\begin{array}{l}55.56 \% \\
(37.31-72.41)\end{array}$ & $\begin{array}{l}20 \% \\
(7.04-45.19)\end{array}$ & $\begin{array}{l}100 \% \\
(79.61-100)\end{array}$ & $\begin{array}{l}60 \% \\
(42.32-75.41)\end{array}$ \\
\hline$-0.50 \mathrm{SD}$ & $\begin{array}{l}100 \% \\
(43.85-100) \\
\end{array}$ & $\begin{array}{l}66.67 \% \\
(47.82-81.36)\end{array}$ & $\begin{array}{l}25 \% \\
(8.89-53.23)\end{array}$ & $\begin{array}{l}100 \% \\
(82.41-100)\end{array}$ & $\begin{array}{l}100 \% \\
(52.12-88.34)\end{array}$ \\
\hline-0.75 SD & $\begin{array}{l}100 \% \\
(43.85-100)\end{array}$ & $\begin{array}{l}74.07 \% \\
(55.32-86.83)\end{array}$ & $\begin{array}{l}30 \% \\
(10.78-60.32)\end{array}$ & $\begin{array}{l}100 \% \\
(83.89-100)\end{array}$ & $\begin{array}{l}76.67 \% \\
(59.07-88.21)\end{array}$ \\
\hline -1 SD & $\begin{array}{l}100 \% \\
(43.85-100) \\
\end{array}$ & $\begin{array}{l}88.89 \% \\
(71.94-96.15) \\
\end{array}$ & $\begin{array}{l}50 \% \\
(18.76-81.24) \\
\end{array}$ & $\begin{array}{l}100 \% \\
86.2-100) \\
\end{array}$ & $\begin{array}{l}90 \% \\
(74.38-96.54) \\
\end{array}$ \\
\hline-2 SD & $\begin{array}{l}66.67 \% \\
(20.77-93.85)\end{array}$ & $\begin{array}{l}100 \% \\
(87.54-100)\end{array}$ & $\begin{array}{l}100 \% \\
(34.24-100)\end{array}$ & $\begin{array}{l}96.43 \% \\
(82.29-99.37)\end{array}$ & $\begin{array}{l}96.67 \% \\
(83.33-99.41)\end{array}$ \\
\hline
\end{tabular}

PPV-Positive Predictive Value NPV- Negative Predictive Value, CI- Confidence Interval

Table-4: Comparison of AIMS percentile rank at 2, 4, 6 months

\begin{tabular}{|l|l|l|}
\hline & Chi-square & P value \\
\hline AIMS at 2 months v/s AIMS at 4 months & 10.952 & .001 (highly significant) \\
\hline AIMS at 2 months v/s AIMS at 6 months & .315 & .575 \\
\hline AIMS at 4 months v/s AIMS at 6 months & .115 & .735 \\
\hline
\end{tabular}




\section{Discussion}

The present study was conducted to compare the effectiveness of Test of Infant Motor Performance as an early marker of motor developmental delay in preterm infants.

Information derived from correlations, although valuable in determining the relationships between early and later development, is limited in discriminating between children with or without developmental delay. To establish a diagnosis or predict outcome, information obtained from sensitivity, specificity, PPV, NPV of a test is needed.

In present study the correlation between TIMP score and AIMS score at 2 months CA was 0.757 $(\mathrm{p}<0.0001)$ and at 4 months CA was 0.874 (p $<0.0001)$. In a study by Suzann K. Campbell assessing the concurrent validity of TIMP with AIMS at 3 months of age showed the correlation between TIMP score and AIMS score to be 0.64 $(\mathrm{p}<0.0001)$ [5]. The smaller correlation compared to present study was because of possibility that large number of raters were used whereas in the present study a single rater performed the scoring which would have reduced the error due to rater administration and scoring. The second possible reason to get greater correlation was the small sample size of the present study as compared to previous studies.

The greater correlation between TIMP and AIMS was observed at 4 months $\mathrm{CA}$ compared to 2 months CA may be because of presence of greater number of items on gross motor abilities on AIMS at 4 months compared to 2 months CA.

The AIMS has been reported to have high concurrent validity with other widely used motor tests, such as Bayley Scale of Infant Development (BSID) motor scale and Peabody Developmental Gross Motor Scale (PD-GMS). Piper and Darrah reported that the Pearson product moment correlation coefficient between the AIMS and BSID scores for infants born at full term was 0.97 and that the correlation coefficient between AIMS and PD-GMS was 0.99. The correlation coefficient between AIMS and BSID motor scale for abnormal infants and infant at risk of developmental disabilities was 0.93 and correlation coefficient between the AIMS and PD-GMS was 0.95. Thus the relation between the BSID or PD-GMS and the AIMS is stronger than that between the TIMP and the AIMS [6].

A possible reason for the smaller correlation between the TIMP and AIMS related to the other research comparing the AIMS to variety of motor tests is differences between the tests in the number of items and rating scales. The TIMP has a much larger number of items than the AIMS during the period around 2 and 4 months of age.

On the basis of previous research on concurrent validity of TIMP with AIMS, however we have taken a cutoff of $-0.25 \mathrm{SD},-0.50 \mathrm{SD},-0.75 \mathrm{SD},-1$ $\mathrm{SD},-2 \mathrm{SD}$ below the mean and cutoff of above or below $10^{\text {th }}$ percentile for AIMS [5].

In the present study cutoff of $-0.25 \mathrm{SD},-0.50 \mathrm{SD}$, $0.75 \mathrm{SD},-1 \mathrm{SD}$ on TIMP at 4 months CA maximized sensitivity at $100 \%$ while using the cutoff score of -2SD maximized specificity at $100 \%$.

In a study by Suzann Campbell in which $-0.25 \mathrm{SD}$ cutoff point on TIMP at 90 days maximized sensitivity at $71 \%$ while using the cutoff score of -1 maximized specificity at $97 \%$ for prediction of 6 months AIMS performance and results were found similar at 12 months. This study showed different cutoff points on TIMP that maximized the sensitivity and specificity for predicting motor performance[7]. In the present study using -0.25 SD,-0.50,-0.75 and -1 SD cutoff points maximized sensitivity at $100 \%$ but at the cost of specificity when compared with -2 SD cutoff point. Thus, a single cutoff cannot be used to optimize both sensitivity and specificity. If the clinician prefers to focus on high sensitivity in order to maximize early identification of infants who may perform poorly, there may be relatively high number of false positives.

In the present study, at 4 months CA the TIMP cutoff score of -1 SD below the mean provided the best sensitivity, specificity, PPV, NPV and diagnostic accuracy. This finding contradicts the previous results that have consistently shown performance at 13 weeks to have better overall predictive results. 
In a study by Suzann K. Campbell et al, sensitivity and specificity of various TIMP cut-off for comparison with AIMS scores above and below the $10^{\text {th }}$ percentile revealed that the best TIMP scores that identified $80 \%$ of infants correctly was a cutoff of -0.50 SD below the mean. It was concluded that TIMP items have much common with those of AIMS at 3 months of age and that both tests identify a similar group of infants as having low motor performance[5].

Suzann K. Campbell et al assessed infants with varying risk and the relation between measures on the TIMP at 7, 30, 60, 90 days after term age and percentile ranks on AIMS. They concluded that TIMP score significantly predicts AIMS percentile rank 6 to 12 months later, but the TIMP at 3 months age has greatest degree of validity for predicting motor performance on the AIMS at 12 months[7]. On the contrary, in our present study TIMP scores at 4 months CA has greater degree of validity for predicting motor performance on the AIMS at 6 months CA. The reason for significant scores at 4 months CA was shorter duration of this study and infants included were born in the late preterm as scores increase systematically with increasing postconceptional age and children with greater medical complication do less well than same age peers as it is evident in the present study where the infants recruited had no greater medical complications in the perinatal period.

Study by Thubi HA Kolobe et al in predicting the motor outcome at preschool age for infants tested at 7, 30, 60 and 90 days after term using TIMP revealed that TIMP score at 90 days after term was the most significant contributor to the prediction with cutoff score of -0.5 SD below the mean which correctly classified $80 \%, 79 \%$, and $87 \%$ of children using a cutoff score of -2 SD on the PDMS-2 at 30 , 60,90 days respectively[8]. The possible reason for the differences in predicting motor outcome in this present study was shorter duration of follow up and the influence of prevalence of a condition in the population being tested as predictive values and to some extent it also influences sensitivity and specificity values in the population being tested.

We suggest that clinicians can use AIMS for making diagnostic decisions regarding delayed motor performance for infants who are at 2-4 months corrected age because of the availability of norms for expected performance as well as data on predictive validity, AIMS with its pictures of motor skills, is an excellent educational tool for parents. For infants born prematurely who have not yet reached the age of their expected date of delivery, we suggest that the TIMP is a useful tool for documenting developmental change over time. We also believe that the larger range of obtainable values on the TIMP (raw scores range from 0-142) is likely to provide greater sensitivity than the AIMS with respect to smaller degrees of changes that are likely to be seen in young infants with motor problems. Having demonstrated ecological validity (Murney and Campbell 1998) with a relationship between TIMP items and care giver handling, TIMP can also be used for parent education [7]. For example: when infants pound their feet on the surface after the legs are released parents can celebrate the appearance of an advanced form of lower extremity function and can use information such as this to understand and encourage extremity motor development.

What this study adds to existing knowledge?TIMP can be easily used and implemented as an early marker of motor developmental delay in preterm infants at the time of discharge and subsequent follow-ups.

\section{Limitations:}

- Small sample size.

- The duration of long term follow up was less.

Further studies are recommended with long duration follow up and with greater sample size and can be compared with the "gold standard" assessment for Indian infants in comparison with TIMP which may provide more evidence as to the effectiveness of TIMP as an early marker of motor developmental delay in preterm infants

\section{Conclusion}

Based on the results of the present study it can be concluded that

- TIMP and AIMS are equally sensitive in the assessment of infant motor performance at 4 months of CA.

- The cutoff score of -1 SD from the mean on TIMP was a better predictor of developmental outcome in this study.

- A high score on TIMP at 4 months CA can be 
used to reassure parents that their child is likely to perform well on motor performance.

Author's Contributions: all authors had equal role in design, work, statistical analysis and manuscript writing.

\section{Conflict of interest: none Funding: None}

Acknowledgements: The authors would like to thank Dr Deepa Metgud, Professor, and all teaching faculty at Department of Pediatric Physiotherapy, KLE University Institute of Physiotherapy for the constant support and guidance in the our academic endeavors. We also thank Dr Manjula Kashinkunti, Associate Professor,

Department of Community Medicine, S.N.Medical College, Bagalkot for guidance in statistical analysis of data in the study.

Funding: Nil, Conflict of interest: None initiated, Perission from IRB: Yes

\section{References}

1. Janet M. Rennie, N. R. C Roberton. Textbook of neonatology. 3rd edition. Edinburg: Churchill livingstone; $1999: 44 p p$

2. Stephens BE, Vohr BR. Neuro development al Outcome of the Premature I nfa nt. Pediatr Clin
NA[Internet]. 2009;56(3):631-46. Available from: http://dx.doi.org/10.1016/j.pcl.2009.03.005

3. Campbell SK. Test-retest reliability of the Test of Infant Motor Performance. Pediatric Physical Therapy. 1999;11:60-66.

4. Campbell SK. The Test of Infant Motor Performance. Test User's Manual Version 2. Chicago, IL: Infant Motor Performance Scales, LLC; 2005.

5. Campbell SK, Kolobe THA. Concurrent Validity of the Test of Infant Motor Performance with the Alberta Infant Motor Scale.Pediatric Physical Therapy. 2000;12:2-9.6

6. Maratha Piper, Johanna Darrah. Motor Assessment of Developing Infant. Philadelphia: W.B. Saunders company;2004.

7. Campbell SK, Kolobe TH, Wright BD, Linacre JM. Validity of the Test of Infant Motor Performance for prediction of 6-, 9- and 12-month scores on the Alberta Infant Motor Scale. DevMedChild Neurol. 2002 Apr;44(4):263-72.

8. Thubi HA Kolobe, Michelle Bulanda, Louisa Susman. Predicting motor outcome at preschool age for infants tested at 7, 30, 60 and 90 days after term age using the Test of Infant Motor Performance. Physical therapy 2004;84:1144-1156.

\section{How to cite this article?}

Diwanmal SB, Dharmayat SR., Biradi MK, Vanaki RN., Pol RR, Yelamali BC. Predicting the effectiveness of Test of Infant Motor Performance as an early marker of motor development delay in preterm infants $\mathrm{J}$ PediatrRes. 2017;4(09):572-579.doi:10. 17511/ijpr.2017.i09.06. 